Nat. Hazards Earth Syst. Sci., 17, 993-1001, 2017

https://doi.org/10.5194/nhess-17-993-2017

(C) Author(s) 2017. This work is distributed under

the Creative Commons Attribution 3.0 License.

\title{
Simple and approximate estimations of future precipitation return values
}

\author{
Rasmus E. Benestad, Kajsa M. Parding, Abdelkader Mezghani, and Anita V. Dyrrdal \\ The Norwegian Meteorological Institute, Henrik Mohns Plass 1, Oslo, 0313, Norway \\ Correspondence to: Rasmus E. Benestad (rasmus.benestad@met.no)
}

Received: 24 June 2016 - Discussion started: 26 July 2016

Revised: 5 April 2017 - Accepted: 28 May 2017 - Published: 3 July 2017

\begin{abstract}
We present estimates of future 20-year return values for $24 \mathrm{~h}$ precipitation based on multi-model ensembles of temperature projections and a crude method to quantify how warmer conditions may influence precipitation intensity. Our results suggest an increase by as much as $40-50 \%$ projected for 2100 for a number of locations in Europe, assuming the high Representative Concentration Pathway (RCP) 8.5 emission scenario. The new strategy was based on combining physical understandings with the limited information available, and it utilised the covariance between the mean seasonal variations in precipitation intensity and the North Atlantic saturation vapour pressure. Rather than estimating the expected values and interannual variability, we tried to estimate an "upper bound" for the response in the precipitation intensity based on the assumption that the seasonal variations in the precipitation intensity are caused by the seasonal variations in temperature. Return values were subsequently derived from the estimated precipitation intensity through a simple and approximate scheme that combined the 1-year $24 \mathrm{~h}$ precipitation return values and downscaled annual wet-day mean precipitation for a 20 -year event. The latter was based on the 95th percentile of a multi-model ensemble spread of downscaled climate model results. We found geographical variations in the shape of the seasonal cycle of the wet-day mean precipitation which suggest that different rain-producing mechanisms dominate in different regions. These differences indicate that the simple method used here to estimate the response of precipitation intensity to temperature was more appropriate for convective precipitation than for orographic rainfall.
\end{abstract}

\section{Introduction}

Extreme precipitation is associated with flooding and landslides and can have detrimental effects on infrastructure and society (Trenberth et al., 2003), as for example during the unusually intense cloudburst in central Copenhagen on 2 July 2011 which caused massive flooding, and the 2002 floods in central and eastern Europe (Hov et al., 2013). Return values are commonly used in planning and design of weather-resilient infrastructure by quantifying the magnitude of a typical extreme event. However, the return values are not stationary, and according to the reinsurance company $\mathrm{Mu}-$ nich Re (Hov et al., 2013), there has been an increase in the annual number of loss events related to weather. Assessments carried out by the Intergovernmental Panel on Climate Change (IPCC) indicate that heavy precipitation will become more severe in already wet areas in the future (Stocker et al., 2013; Field et al., 2012). These assessments have largely been based on global climate model (GCM) output and have not made use of additional local information such as meteorological observations. One of the difficulties of using observational data is the patchy character of the information because of missing data and short records. Global climate models are not designed to represent local precipitation statistics corresponding to rain gauge data, but are expected to reproduce the nature of large-scale (regional and global) phenomena and processes seen in the atmosphere and oceans. Also, some elements are reproduced with higher skill than others. In other words, GCMs provide a more reliable picture of the temperature aggregated over larger spatial scales than of grid-box precipitation estimates (Takayabu et al., 2015), and their ability to simulate large-scale features can be utilised for inferring changes to local precipitation through downscaling (Benestad et al., 2008). This caveat also applies to 
regional climate models (RCMs), which also have a minimum skillful scale (Takayabu et al., 2015) and have a limited ability to reproduce the observed precipitation statistics (Orskaug et al., 2011; Benestad and Haugen, 2007). Nevertheless, RCMs have been used to study precipitation extremes (e.g. Frei et al., 2006), although the heavy computational demands have limited analysis to a small number of GCMs which means that the ensembles do not provide a realistic range of possible outcomes associated with natural variability and model uncertainty (Deser et al., 2012).

Traditional methods of estimating return values that make use of extreme value theory (EVT) are sensitive to sampling fluctuations and require long data records to avoid extrapolation of extreme characteristics (Coles, 2001; Papalexiou and Koutsoyiannis, 2013). Extreme precipitation modelled through EVT usually describes amounts that are far out in the tail of the distribution and associated with low probability, and the estimates may change when new extremes are sampled. Most uses of EVT also assume stationarity, although there are ways to account for trends (Cheng et al., 2014).

Local precipitation has been notoriously difficult to predict (Stocker et al., 2013; Field et al., 2012; Arkin et al., 1994); one reason may be that it has involved quantities such as the monthly mean precipitation that are calculated from a blend of different (both dry- and wet-day) conditions and phenomena without accounting for these differences. There are many different types of phenomena that generate precipitation, e.g. the formation of nimbostratus, mid-latitude cyclones, fronts, atmospheric rivers, convection and warm and cold initiation of rain (Fleagle and Businger, 1980; Berg et al., 2013; Trenberth et al., 2003). Some of these have a stronger presence in certain regions and seasons. For instance, convective precipitation is typically a summer phenomenon at mid-to-high latitudes, whereas mid-latitude cyclones are more pronounced in autumn, winter and spring. Another reason for the limited success may be the small sample size in calculations of the mean precipitation for locations and seasons where it rains rarely. For example, if it rains less than $30 \%$ of the total number of days in a month, the monthly average precipitation is based on less than 10 values. The quantification of future extreme precipitation is associated with uncertainties from a number of sources (e.g. model imperfections, sparsity of data, sensitivity to random variations in small samples constituting the tail of the distribution, non-stationarity and the representation of natural variability). Large multi-model ensembles can be used to explore the natural variability of the climate system, although the range of the ensembles also includes other sources of uncertainty and variability, and some ensemble members may be inter-dependent (Sanderson et al., 2015).

Moderate extremes in $24 \mathrm{~h}$ precipitation amounts $(X)$ can be approximated with an exponential distribution (Benestad et al., 2012a, b; Benestad, 2013), which is described with one parameter - the wet-day mean $\mu$ - and its percentile $\left(q_{\mathrm{p}}\right)$ can be estimated as $q_{\mathrm{p}}=-\ln (1-p) \mu$. The exponential distri-

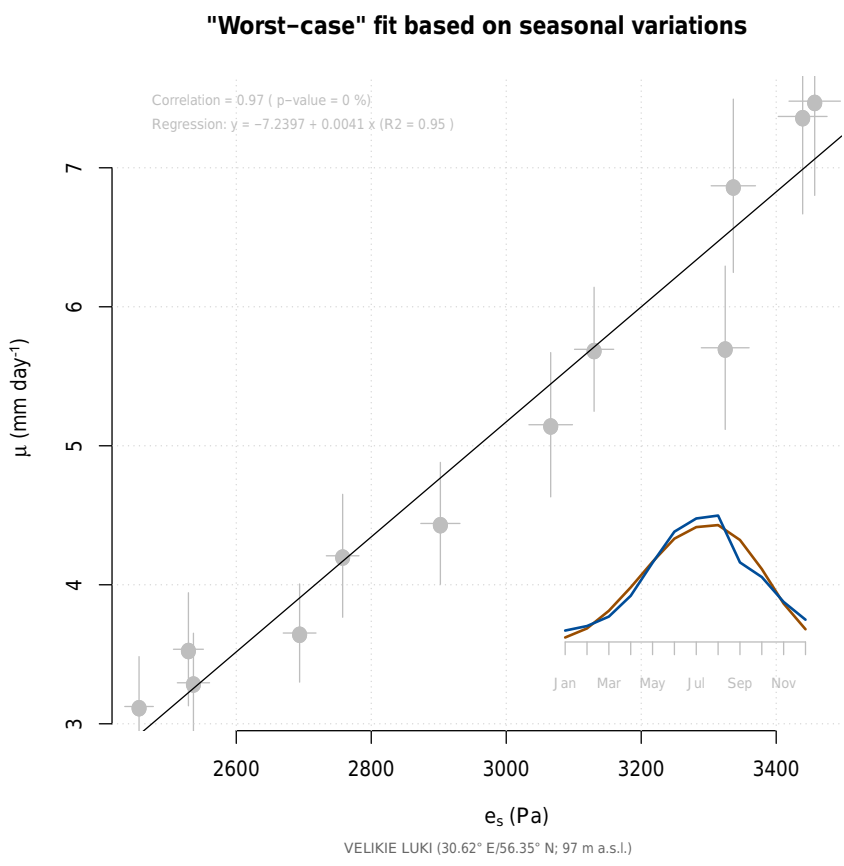

Figure 1. A comparison between the mean seasonal cycle in the saturation vapour pressure ( $x$ axis) and the wet-day mean ( $y$ axis) for the site Velikie Luki, Russia. The error bars indicate 2 standard deviations of the year-to-year variations in the two variables. An inset shows the standardised seasonal cycles, both variables peaking in July-August (red line $=e_{\mathrm{S}}$, blue line $=\mu$ ).

bution can be used to estimate changes in the moderate upper tail of the statistical distribution, assuming that these follow changes in the bulk characteristics where the probability adds up to unity (Benestad and Mezghani, 2015). This approximation has been tested against daily rain-gauge records from around the world, confirming that the exponential distribution $\left(q_{\mathrm{p}}=-\ln (1-p) \mu\right)$ predicts the observed precipitation percentiles with high accuracy for low-to-moderately heavy precipitation amounts (Fig. S1 in the Supplement). This means that $\mu$ is useful for risk analysis to estimate upper percentiles of $24 \mathrm{~h}$ precipitation amounts because the 95th percentile $q_{95}$ is expected to change proportionally with $\mu$ (Benestad, 2013; Benestad and Mezghani, 2015).

\section{Data and methods}

Our objective was to get estimates of future extreme precipitation that were robust to outliers in situations when local observations are limited and to avoid some of the caveats described above. We therefore explored a method of extracting information about extreme precipitation from the multitude of data sources available while reducing the uncertainty associated with small sample sizes and blended conditions. Our analysis drew on available and relevant information concerning precipitation, for instance geographical variations, sea- 
sonal variations, ensemble spread and different physical processes present during wet and dry days.

The estimated precipitation change was based on the change in temperature and did not explicitly take atmospheric circulation changes or feedback processes into consideration. This change can, for all intents and purposes, be interpreted as a zeroth-order measure of an "upper bound" of change in precipitation intensity associated with increased temperature, rather than the most likely value. Attributing all of the seasonal variations in the precipitation intensity to its covariance with temperature may inflate the role of the temperature, as other factors exhibit a similar mean seasonal cycle and may have an influence on the precipitation intensity. For this reason, we use the terms upper bound and potential sensitivity. It is also true that other unaccounted-for processes possibly may influence precipitation intensity in a nonlinear fashion and possibly result in even higher intensities if they also change in the future. However, as long as (a) such factors have an approximately linear dependency on the temperature and (b) the temperature may be taken as a proxy for climate change, then this simple assumption may provide a reasonable figure. This simple method differs from traditional methods in that rather than attempting to specify the most likely value, it estimates a kind of upper bound of the systematic response of extreme precipitation to changes in temperature. We henceforth describe this relation as the potential sensitivity (PS) since the calibration used the covariance of the mean annual variation that may exaggerate the effect of the temperature. This is described in more details below.

Our approach was based on empirical-statistical downscaling (ESD) applied to a large multi-model ensemble to provide estimates of return values for heavy precipitation, and is an alternative to EVT-based approaches. It provided an estimate that was more approximate and crude, but less sensitive to outliers because a larger portion of the data sample is used.

The Supplement provides more details and explanations of the strategy, as well as the R scripts used to perform the analysis. The calculations and graphics were produced with the open-source R package "esd" (Benestad et al., 2015). The data used in this analysis are available from the reference provided in Benestad (2017).

\subsection{Data}

Precipitation observations were obtained from the daily European Climate Assessment, ECA\&D, data set (Klein Tank et al., 2002) for 1032 stations in northern Europe with data available for the time period 1961-2014 (Fig. 2). Surface temperature data from the National Centers for Environmental Prediction/National Center for Atmospheric Research (NCEP/NCAR) Reanalysis 1 (Kalnay et al., 1996) over a selected North Atlantic domain $\left(100^{\circ} \mathrm{W}-30^{\circ} \mathrm{E} / 0^{\circ} \mathrm{N}-40^{\circ} \mathrm{N}\right.$; see Fig. S2) were used to calculate the predictors for the
Table 1. Summary of the CMIP5 experiments. RCP4.5 was used as default here, whereas RCP2.6 and 8.5 were taken as lower and upper limits based on different emission scenarios.

\begin{tabular}{ll}
\hline Ensemble & $\begin{array}{l}\text { Total ensemble size } \\
\text { (with duplicated models) }\end{array}$ \\
\hline RCP4.5 & 108 runs \\
RCP2.6 & 81 runs \\
RCP8.5 & 65 runs \\
\hline
\end{tabular}

downscaling, and corresponding projections from the CMIP5 ensembles of GCMs assuming the Representative Concentration Pathway (RCP) 2.6, 4.5 and 8.5 scenarios (Taylor et al., 2012) were used for the projections of future change (Table 1). We used the NCEP/NCAR Reanalysis 1 because the data covered the 1961-2014 period and because it provided a representation for the surface temperature that was comparable to that of the CMIP5 GCMs.

\subsection{Downscaling method}

\subsubsection{Predictand: annual wet-day mean precipitation}

A traditional approach for modelling and analysing precipitation typically involves the monthly mean precipitation $(\bar{X})$, but in this study, we instead downscaled the wet-day mean, $\mu$. In this analysis we used $\mu$ to represent the wet-day mean precipitation in general, reflecting both the annual wet-day mean precipitation and the mean seasonal variations in the wet-day mean precipitation estimated for the 12 calendar months. The mean precipitation was not the optimal quantity for describing precipitation statistics because in most places it does not rain every day, and the proportion of wet days to total number of days in a monthly sample can have implications for the estimation of the statistical parameters describing the distribution. The mean precipitation can be expressed as the product of the wet-day frequency $\left(f_{\mathrm{w}}\right)$ and $\mu$ according to $\bar{X}=f_{\mathrm{w}} \mu$. A comparison between the seasonal dependence of $\bar{X}, \mu$ and wet-day frequency $f_{\mathrm{w}}$ indicated a stronger seasonal cycle in $\mu$ than in $f_{\mathrm{w}}$ and $\bar{X}$ (see Fig. S3). The weaker seasonal cycle in $\bar{X}$ was due to the blending of different types of weather conditions in the mean precipitation. The strong seasonal cycle of $\mu$ indicated a sensitivity to climatological variations, which is an important requirement for the statistical downscaling strategy proposed here.

\subsubsection{Predictor: the saturation vapour pressure}

We assumed that the vapour saturation pressure, $e_{\mathrm{S}}$, is more linearly related to the atmospheric water content and precipitation than the temperature, and hence we used $e_{\mathrm{s}}$ as a predictor in the downscaling of the annual wet-day mean precipitation $\mu$ (Fujibe, 2013; Pall et al., 2007; Benestad and Mezghani, 2015). The saturation vapour pressure was esti- 

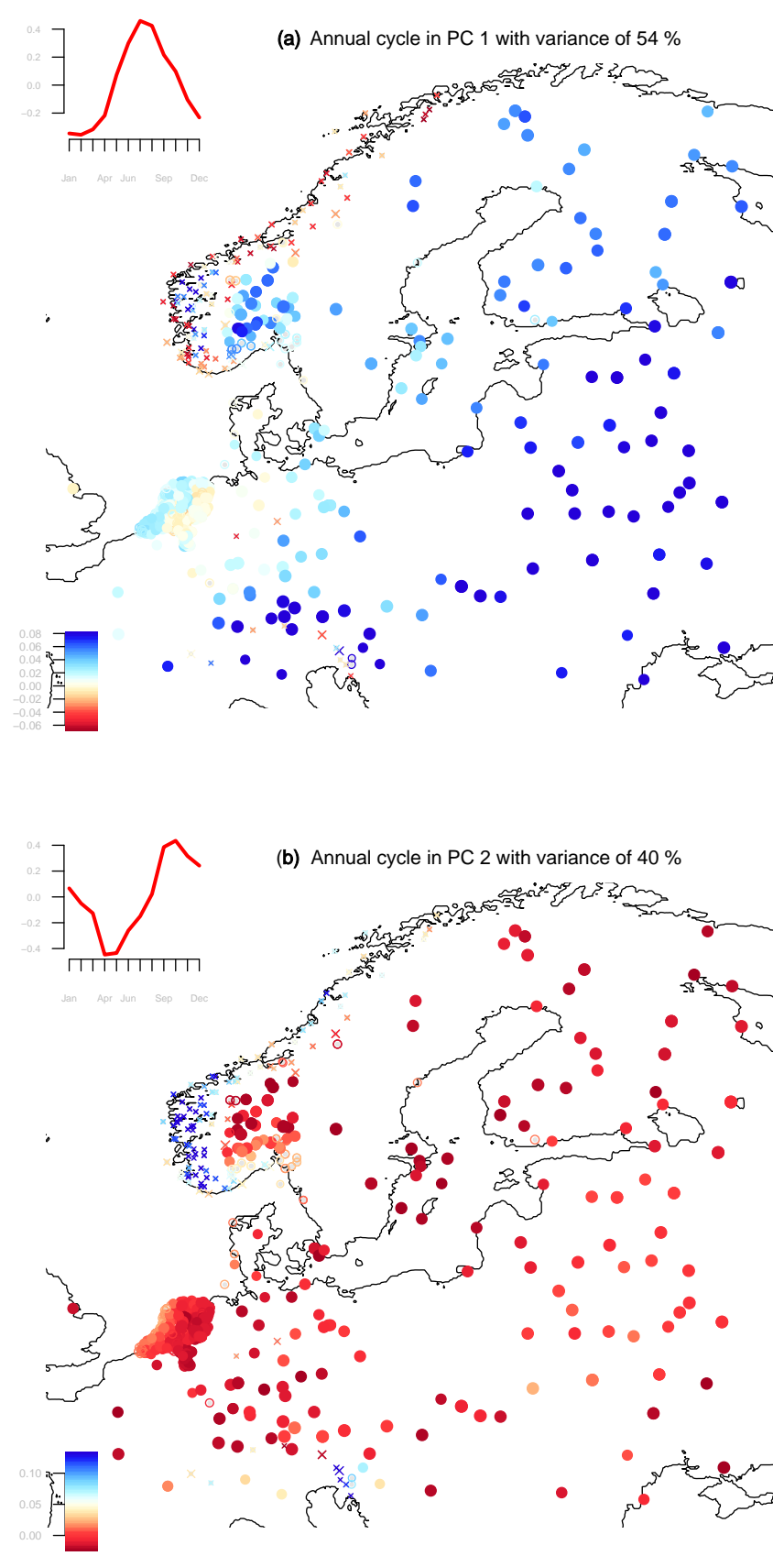

Figure 2. The weights for the two leading principal components $(\mathbf{a}, \mathbf{b})$ of the seasonal cycle of the wet-day mean precipitation $\mu$ in the 1032 rain gauge records. The colour of the symbols indicates how strongly the shape is present in the local seasonal cycle, and the size reflects $R^{2}$ from the regression analysis between $e_{\mathrm{S}}$ and $\mu$ (see Fig. S5). Filled circles were used for locations with $R^{2}>0.6$, hollow circles for $0.6 \geq R^{2}>0.4$ and crosses indicate locations with $R^{2}<0.4$. The shape of the seasonal cycle principal component for $\mu$ is shown in the inset (top left of each panel).

mated from the surface temperature $(0.995 \sigma$ level $), T$.

$e_{\mathrm{S}}=10^{(11.40-2353 / T)}$
This approximation was based on integration of the Clausius-Clapeyron equation, assuming a constant latent heat of vaporisation (see Eq. 2.89 in Fleagle and Businger, 1980). The mean seasonal variations in the regional average $e_{\mathrm{S}}$ over the North Atlantic domain was used as predictor for $\mu$, based on its mean seasonal variation (Fig. 1); our reasoning was that it can be considered as the source region for humidity in Europe. The domain was set after some trials for a few test stations, but no systematic study or tuning of the predictor domain was conducted. The predictor index was calculated from gridded temperature data from reanalyses and global climate models (GCMs) and was then spatially and temporally aggregated where monthly gridded $e_{\mathrm{s}}$ values were estimated according to Eq. (1) and surface temperatures from the multi-model ensemble, and were used to downscale an ensemble of local results of annual wet-day mean precipitation $\hat{\mu}$ (here $\hat{\mu}$ is used for predicted annual mean).

\subsubsection{The empirical-statistical model}

A model for predicting the annual wet-day mean precipitation $\hat{\mu}$ can be constructed as a sum of a constant, $\beta_{0}$, a term depending on the saturation vapour pressure, $\beta_{T} e_{\mathrm{s}}$, and a Gaussian noise term, $N(0, \sigma)$, assuming that factors other than temperature that are affecting wet-day precipitation are stochastic and stationary:

$\hat{\mu}=\beta_{0}+\beta_{T} e_{\mathrm{s}}+N(0, \sigma)$.

The assumptions about other factors being stationary and stochastic is partly based on the heuristic notion of physical interdependencies between various aspects of the planetary atmosphere in general and that the temperature is a proxy for such influences. One example may be the cloud top height which is expected to be influenced by the convective available potential energy (CAPE) that is sensitive to temperatures. We used the observed standard deviation of $\mu$ in the month with the highest interannual variability as an estimate of the standard deviation $\sigma$ of the noise term $N$, which in this case was August. We calculated the coefficients $\beta_{0}$ and $\beta_{T}$ using linear regression analysis between the mean seasonal cycle of the observed monthly mean $\mu$ and the corresponding seasonal cycle of the regionally averaged $e_{\mathrm{s}}$ calculated from reanalysis temperature data from the Atlantic domain, as described in Sect. 2.2.2. The coefficient $\beta_{T}$ is the scaling ratio which we refer to as the potential sensitivity.

Annual mean time series of $\hat{\mu}$ were then derived by applying the downscaling models to annual mean $e_{\mathrm{S}}$ time series obtained from reanalysis or GCM temperature data from the same domain. The GCM results were not bias-adjusted; however, the use of large-scale $\left(100^{\circ} \mathrm{W}-30^{\circ} \mathrm{E} / 0-40^{\circ} \mathrm{N}\right)$ spatially and annually aggregated mean helped mitigating the effects from systematic model biases. The model represented an approximation of the systematic effect that temperature changes can have on $\mu$, rather than a most likely value. It is possible that other factors that play a role in precipitation 
also exhibit a seasonal cycle and interfere with the regression analysis so that the coefficient is weaker or stronger than the true influence of temperature on precipitation.

A $90 \%$ uncertainty range for $\hat{\mu}$ was estimated for the projections based on the ensembles of downscaled results, taken as the limit between the 5th and 95th percentiles (see, e.g., Fig. S4). This interval included the noise term $N(0, \sigma)$, and captured the observed year-to-year variations as well as model differences (Deser et al., 2012). We assumed that the multi-model ensemble spread for any given year could approximately represent the typical year-to-year variance, which meant that the 95th percentile for $\hat{\mu}$, which we henceforth refer to as $\hat{\mu}_{95}$, could be used as a proxy for the value to be exceeded once in 20 years (Benestad, 2016) (the 20-year event has a probability of $0.05(1 / 20)$ of occurring in a given year, and the 95 th percentile represents a limit that only $5 \%$ (1 in 20) of the distribution exceeds).

\subsection{Return value probabilities}

To estimate future return values based on the downscaled $\hat{\mu}$, we again assumed that the wet-day precipitation amount was exponentially distributed and that the probability for $24 \mathrm{~h}$ precipitation exceeding a critical threshold $x$ could be calculated as follows:

$\operatorname{Pr}(X>x) \approx f_{\mathrm{w}} e^{-x / \mu}$,

where $f_{\mathrm{w}}$ was the wet-day frequency (Benestad and Mezghani, 2015). Previous analysis suggest that the exponential distribution gives a reasonable description of the probabilities for moderate precipitation events such as the 95-percentile, but is not expected to be suitable for rare extremes much beyond the 20-year return level (Benestad, 2013).

The probability associated with the 1-year return value of $24 \mathrm{~h}$ precipitation is approximately $\operatorname{Pr}(X>x)=1 / 365.25$, and the corresponding threshold value was approximated according to

$x_{1 \text { year }} \approx \mu \ln \left(365.25 f_{\mathrm{w}}\right)$.

Previous comparison between the return values based on Eq. (4) and general extreme value theory, has suggested that they give roughly similar results (Benestad and Mezghani, 2015). A test of Eq. (4) indicated that the return values scale with $\mu$ : values of $x_{1}$ year that were associated with high percentiles and low values of $\hat{\mu}$ approximately corresponded to $x_{1}$ year with low percentiles and high values of $\hat{\mu}$ (Fig. S1). Based on Eq. (4), we made a rough estimate of the 20-year return value for the $24 \mathrm{~h}$ precipitation amount ( $x_{20}$ year $)$ by replacing $\mu$ with the 20-year return value of the annual wetday mean. The estimate for $\hat{x}_{20}$ year was calculated based on the downscaled annual wet-day mean precipitation, using the 95th percentile $\hat{\mu}_{95}$ as a proxy for the 20 -year return values:

$\hat{x}_{20 \text { year }}=\hat{\mu}_{95} \ln \left(365.25 f_{\mathrm{w}}\right)$.
In calculating future return values, we neglected changes in $f_{\mathrm{w}}$ and simply assumed that it will remain constant. Previous analysis has indicated that the wet-day frequency is strongly influenced by circulation patterns (Benestad and Mezghani, 2015), and that it is closely connected to slow natural variations such as the North Atlantic Oscillation (NAO) (Hurrell, 1995). Such natural variations are difficult to predict and there is little evidence of a systematic shift in the frequency of different circulation patterns.

\subsection{Principle component analysis of the seasonal cycle}

Principal component analysis (PCA) was used to extract the most dominant shapes of the seasonal cycle in $\mu$ amongst the observation sites (Fig. 2). The mean seasonal cycle was estimated for each site and used to construct a data matrix $\mathbf{X}$ with 12 columns (one for each month) and $n$ rows (one for each site). Singular value decomposition (SVD) was then used to compute the principal components: $\mathbf{U} \boldsymbol{\Sigma} \mathbf{V}^{T}=\mathbf{X}$, where $\mathbf{U}$ is the left inverse, $\mathbf{V}$ the right inverse and $\boldsymbol{\Sigma}$ is a diagonal matrix holding the eigenvalues (Press et al., 1989; Strang, 1988). The procedure deconstructed the data into a set of shapes of the seasonal cycle, corresponding eigenvalues that described the explained variance and a spatial matrix that described the relative strength of each shape at the different locations.

\section{Results and discussion}

\subsection{Potential sensitivity and the seasonal cycles in $\mu$ and $e_{\mathrm{s}}$}

The mean seasonal cycles of $\mu$ at many European locations co-varied with the mean seasonal cycle of $e_{\mathrm{s}}$ in the North Atlantic domain. This can be seen as a validation of the assumptions underlying the empirical model, because the downscaling models were based on the regression between the seasonal cycles of $e_{\mathrm{s}}$ and $\mu$ (Eq. 2). Figure 1 provides an example of a scatter plot between the mean seasonal variations in $e_{\mathrm{S}}(x$ axis) and the corresponding cycle in $\mu$ (y axis) for one location (Velikie Luki, Russia). The example in Fig. 1 was not unique: there was a high and statistically significant correlation $\left(R^{2}>0.6\right.$; Fig. S5) between the seasonal cycle of these two quantities for many of the rain gauge records (612 of the 1032 stations). The majority of the locations with a poor fit $\left(R^{2}<0.6\right)$ were found along the western coast of Norway and south-east of the Alps, while inland sites and locations in central Europe had higher $R^{2}$ values (see Fig. 2 where the size of the markers is proportional to $R^{2}$ ). This indicated that a linear relationship between $\mu$ and $e_{\mathrm{s}}$ could not be expected in regions where orographic precipitation was dominant. Downscaled projections were carried out only for the locations with a good fit $\left(R^{2}>0.6\right)$.

It was also evident that there were pronounced year-toyear variations in the wet-day mean (vertical error bars in Fig. 1) which were not related to the temperature, suggesting 
that factors other than temperature also played a role in precipitation variations. The downscaling strategy adopted here was designed to evaluate the maximum potential effect of temperature changes on the wet-day mean precipitation, and the scaling factor between the two is described as the potential sensitivity. Since other processes also influenced precipitation, the method could not be expected to reproduce past interannual variability, but it could be used to obtain a rough estimate of the effect of temperature changes on precipitation.

Figure 2 presents maps showing the two major components of the mean seasonal cycle in $\mu$, which together accounted for $94 \%$ of the variability for the 1032 locations examined. The spatial patterns in the principle components (PC) revealed different seasonal cycles of precipitation along the mountainous western coast of Norway and close to the Alps compared to the rest of Europe, probably related to orographic effects. There was a gradient in the shape of the mean seasonal cycle in $\mu$ with the distance from the coast that was particularly visible over the Netherlands. Inland sites indicated higher precipitation intensities during July and August, which could be associated with convective rainfall. We found a positive correlation between the spatial vector of the leading PCs and $R^{2}$ of the seasonal cycles of $e_{\mathrm{S}}$ and $\mu: 0.82$ (with a $90 \%$ uncertainty range of $0.80,0.84$ ), but negative correlation for mode $2(-0.84 ;-0.86,-0.82)$ and no significant correlation for mode $3(0.00 ;-0.06,0.06)$. This indicated that the dominant shapes of the seasonal cycle of $\mu$ in Europe were associated with a strong connection to the North Atlantic temperature.

\subsection{Projections of future precipitation}

Projected values of the annual mean wet-day mean, $\hat{\mu}$, based on the downscaling model (Eq. 2) applied to the CMIP5 ensemble, are shown in Fig. 3. The downscaled results suggested an increase of up to $13 \%$ in the wet-day mean from 2010 to 2100 , assuming the RCP4.5 emission scenario (Stocker et al., 2013), and as much as $38 \%$ at many of the locations given the high emission scenario RCP8.5. The most extreme estimate was an $85 \%$ increase at Sihccajavri (Norway). Since the wet-day precipitation amount approximately followed an exponential distribution, the proportional change in any percentile was the same as for $\mu$. The inset in Fig. 3 shows estimated changes for the emission scenarios RCP4.5, 2.6 and 8.5 for both the ensemble mean and 95th percentile.

An analysis of historical observations provided some indication of skill of the downscaling models in terms of predicting trends of $\mu$ based on the North Atlantic temperature (Fig. S6). The historical trends exhibited a more pronounced scatter than the predicted trends, suggesting that factors other than the sea-surface temperature also had influenced the long-term changes. For most locations, there was an increase in $\mu$ between 1961 and 2014, typically $0.1 \mathrm{~mm} \mathrm{day}^{-1}$ per decade (Fig. S6-S7).
Table 2. Summary of the projected change from 2010 to 2100 in the 20 -year return value for $24 \mathrm{~h}$ precipitation under the assumption of stationary wet-day frequency. The sample comprises the 615 locations shown in Fig. 3. The numbers represent the change in percentage with respect to year 2010 .

\begin{tabular}{lrrrrrr}
\hline Ensemble & Min. & $q 25$ & Median & Mean & $q 75$ & Max. \\
\hline RCP2.6 & $4 \%$ & $5 \%$ & $6 \%$ & $6 \%$ & $7 \%$ & $14 \%$ \\
RCP4.5 & $7 \%$ & $10 \%$ & $11 \%$ & $13 \%$ & $15 \%$ & $28 \%$ \\
RCP8.5 & $22 \%$ & $28 \%$ & $33 \%$ & $38 \%$ & $44 \%$ & $85 \%$ \\
\hline
\end{tabular}

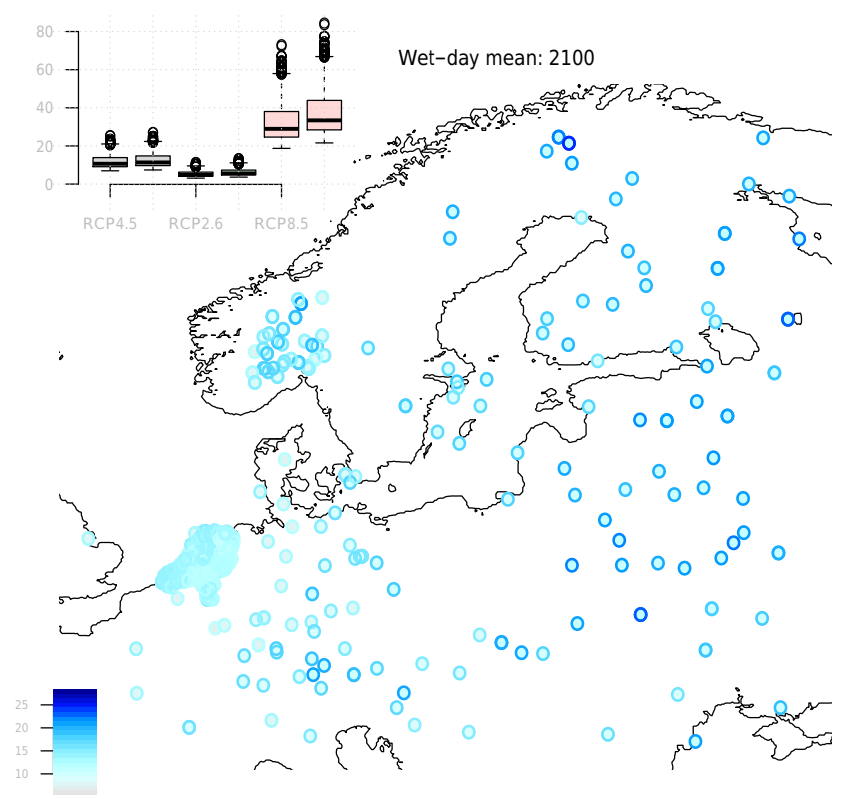

Figure 3. Projected local change from 2010 to 2100 in the ensemble mean and 95th percentile annual mean $\mu$ for the RCP4.5 emission scenario. The colour of the inner part of the symbols indicates changes in the ensemble mean and the outer part the 95th percentile in terms of percentages since 2010. The inset shows a boxplot of the projected change in $\mu$, both for the ensemble mean (left) and the 95th percentile (right) of emission scenarios RCP4.5, 2.6 and 8.5 .

Estimates of future 20-year return values (Eq. 5) based on $\hat{\mu}_{95}$ and assuming a constant value of the wet-day frequency, $f_{\mathrm{w}}$, are shown in Table 2. Based on downscaling of the RCP4.5 scenario, the 20-year return values may increase by between 7 and $28 \%$ by 2100 (ensemble median: $11 \%$ ), or assuming the high emission scenario RCP8.5, between 22 and $85 \%$ (ensemble median: $33 \%$ ). Nevertheless, changes in $f_{\mathrm{w}}$ may also influence return values, and an increase in the number of rainy days would imply an even stronger change in return values.

The historical $f_{\mathrm{w}}$ trends at the stations tend to cluster roughly around zero (Fig. S8). However, studying the geographical pattern of trends, we saw a general increase in southern Scandinavia and the Netherlands for the period 
1961-2014, but a less coherent pattern elsewhere (Fig. S9). This implied that factors other than the North Atlantic temperature may also have played a role in past trends and future precipitation changes. The wet-day frequency was strongly influenced by the circulation patterns (Benestad and Mezghani, 2015) and could potentially be predicted based on the mean sea-level pressure, but here we have focused on the influence of temperature changes on the precipitation.

\subsection{Validation of results}

In order to assess the veracity of our results, we performed an independent test to examine the dependency of $\mu$ on temperature, consisting of a regression analysis comparing the spatial variations of the mean of $\mu$ and $e_{\mathrm{S}}$ calculated from local temperature measurements (Benestad, 2007) (see Figs. S10 S11). The test was limited to locations where both temperature and precipitation observations were available and did not involve the regionally averaged temperature of the North Atlantic domain. The geographical variations in the relationship between $\mu$ and $e_{\mathrm{S}}$ were consistent with the regression coefficients from the downscaling models (Eq. 2, Fig. 3) within the range of estimated error margins (Fig. S11). An exception was seen in stations located in western Norway and southeast of the Alps, where the seasonal cycle regression also showed a weak relationship between $\mu$ and $e_{\mathrm{s}}$. The fact that the link between $\mu$ and $e_{\mathrm{s}}$ was found in both time and space provided a stronger indicator of a physical link than if it were limited to only the time dimension.

\section{Summary and conclusions}

We have proposed a novel and simple method for obtaining an approximate estimate of changes in the return values for $24 \mathrm{~h}$ precipitation caused by a temperature change, taking all precipitation relevant processes into account. This method made use of the information embedded in the seasonal cycle, physical conditions and multi-model ensembles to provide a rough estimate of the potential sensitivity of precipitation intensity to temperature. The results suggested that the zerothorder estimate for an upper bound of the 20-year return value for many European locations increases by $40-50 \%$ by 2100 for the RCP8.5 scenario, rather than the exact or most likely value.

One of the benefits of the proposed strategy for downscaling $\mu$ is that the description of the seasonal cycle does not require long data records and hence may provide a means for estimating a zeroth-order value for the potential sensitivity and an upper bound to the change in rainfall statistics in regions with limited observations. This strategy can be used for other mid-latitude locations, but further analysis is needed to see if it is applicable to the monsoon regions where the temperature is at maximum before the rains start. An alternative approach could be to estimate future changes in $\mu$ based on downscaled local temperature from GCMs and a similar regression model as used in the test described above.

The approach was based on a set of assumptions: (a) the maximum seasonal mean response of the wet-day mean precipitation to the seasonal variations in temperature is represented by a proportional change, (b) the 95th percentile of the annual wet-day mean precipitation from large multi-model ensembles (e.g. CMIP5) can be used to represent a 20-year event and (c) the wet-day frequency is stationary. On the one hand, this new strategy is less rigorous than traditional extreme value statistics; on the other hand, it is more robust to outliers even in cases when the available information is limited.

Another potential weakness of the study is the use of the multi-model ensembles as a representation of natural climate variability. These "ensembles of opportunity" involve non-independent members and cannot really be considered a random data sample (Sanderson et al., 2015). However, internal variability dominates the variance on regional and local scales and gives a spread that is comparable to the observed variations even in single-model ensembles (Deser et al., 2012).

Data availability. Data used in this analysis are available from figshare (https://doi.org/10.6084/m9.figshare.5047789; see Benestad, 2017). The analysis was based on the esd package (https://doi.org/10.5281/zenodo.29385; see Benestad et al., 2015).

\section{The Supplement related to this article is available online at https://doi.org/10.5194/nhess-17-993-2017- supplement.}

Competing interests. The authors declare that they have no conflict of interest.

Acknowledgements. The methods and results produced for this paper were connected to research carried out for the H2020 EU-Circle (GA no. 653824), Nordforsk eSACP. The work was supported by the Norwegian Meteorological Institute.

Edited by: Thorsten Wagener

Reviewed by: Reik Donner and two anonymous referees

\section{References}

Arkin, P. A., Joyce, R., and Janowiak, J. E.: The estimation of global monthly mean rainfall using infrared satellite data: The GOES precipitation index (GPI), Remote Sensing Reviews, 11, 107124, https://doi.org/10.1080/02757259409532261, 1994.

Benestad, R.: Novel Methods for Inferring Future Changes in Extreme Rainfall over Northern Europe, Clim. Res., 34, 195-210, 2007. 
Benestad, R. E.: Association between trends in daily rainfall percentiles and the global mean temperature, J. Geophys. Res.Atmos., 118, 10802-10810, https://doi.org/10.1002/jgrd.50814, 2013.

Benestad, R. E.: A Mental Picture of the Greenhouse Effect: A Pedagogic Explanation, Theor. Appl. Climatol., 128, 679-688, https://doi.org/10.1007/s00704-016-1732-y, 2016.

Benestad, R. E.: Simple and approximate estimation of future precipitation return-values, https://doi.org/10.6084/m9.figshare.5047789.v1, 2017.

Benestad, R. E. and Haugen, J. E.: On Complex Extremes: Flood hazards and combined high spring-time precipitation and temperature in Norway, Climatic Change, 85, 381-406, 2007.

Benestad, R. E. and Mezghani, A.: On downscaling probabilities for heavy 24-hour precipitation events at seasonal-to-decadal scales, Tellus A, 67, 25954, https://doi.org/10.3402/tellusa.v67.25954, 2015.

Benestad, R. E., Hanssen-Bauer, I., and Chen, D.: EmpiricalStatistical Downscaling, World Scientific, Singapore, 2008.

Benestad, R., Nychka, D., and Mearns, L. O.: Spatially and temporally consistent prediction of heavy precipitation from mean values, Nature Climate Change, 2, 544-547, 2012a.

Benestad, R., Nychka, D., and Mearns, L. O.: Specification of wetday daily rainfall quantiles from the mean value, Tellus A, 64, 14981, https://doi.org/10.3402/tellusa.v64i0.14981, 2012b.

Benestad, R. E., Mezghani, A., and Parding, K. M.: esd V1.0, https://doi.org/10.5281/zenodo.29385, 2015.

Berg, P., Moseley, C., and Haerter, J. O.: Strong increase in convective precipitation in response to higher temperatures, Nat. Geosci., 6, 181-185, https://doi.org/10.1038/ngeo1731, 2013.

Cheng, L., AghaKouchak, A., Gilleland, E., and Katz, R. W.: Non-stationary extreme value analysis in a changing climate, Climatic Change, 127, 353-369, https://doi.org/10.1007/s10584014-1254-5, 2014.

Coles, S. G.: An Introduction to Statistical Modeling of Extreme Values, Springer, London, 2001.

Deser, C., Knutti, R., Solomon, S., and Phillips, A. S.: Communication of the role of natural variability in future North American climate, Nature Climate Change, 2, 775-779, 2012.

Field, C., Barros, V., Stocker, T. F., Qin, D., Dokken, D. J., Ebi, K. L., Mastrandrea, M. D., Mach, K. J., Plattner, G.-K., Allen, S. K., Tignor, M., and Midgley, P. M., (Eds.): Managing the Risks of Extreme Events and Disasters to Advance Climate Change Adaptation. A Special Report of Working Groups I and II of the Intergovernmental Panel on Climate Change, Cambridge University Press, Cambridge, UK, and New York, NY, USA, 2012.

Fleagle, R. G. and Businger, J. A.: An Introduction to Atmospheric Physics, vol. 25 of International Geophysics Series, 2 Edn., Academic Press, Orlando, 1980.

Frei, C., Schöll, R., Fukutome, S., Schmidli, J., and Vidale, P. L.: Future change of precipitation extremes in Europe: Intercomparison of scenarios from regional climate models, J. Geophys. Res., 111, D06105, https://doi.org/10.1029/2005JD005965, 2006.

Fujibe, F.: Clausius-Clapeyron-like relationship in multidecadal changes of extreme short-term precipitation and temperature in Japan: Multidecadal changes of extreme precipitation and temperature in Japan, Atmos. Sci. Lett., 14, 127-132, https://doi.org/10.1002/as12.428, 2013.
Hov, O., Cubasch, C., Fischer, E., Hoppe, P., Iversen, T., Kvamsto, N., Kundzewicz, Z., Rezacova, D., Rios, D., Santos, F., Schadler, B., Veisz, O., Zerefos, G., Benestad, R., Murlis, J., Donat, M., Leckebusch, G., and Ulbrich, U.: Extreme Weather Events in Europe: preparing for climate change adaptation, Tech. rep., MET Norway, The Norwegian Academy of Sciences and Letters (DNVA), European Academies Science Advicery Council (EASAC), 2013.

Hurrell, J. W.: Decadal trends in the North Atlantic Oscillation: Regional temperatures and precipitation, Science, 269, 676-679, 1995.

Kalnay, E., Kanamitsu, M., Kistler, R., Collins, W., Deaven, D., Gandin, L., Iredell, M., Saha, S., White, G., Wollen, J., Zhu, Y., Chelliah, M., Ebisuzaki, W., Higgins, W., Janowiak, J., Mo, K. C., Ropelewski, C., Wang, J., Leetmaa, A., Reynolds, R., Jenne, R., and Joseph, D.: The NCEP/NCAR 40-Year Reanalysis Project, B. Am. Meteorol. Soc., 77, 437-471, 1996.

Klein Tank, A. J. B. W., Konnen, G. P., Böhm, R., Demarée, G., Gocheva, A., Mileta, M., Pashiardis, S., Hejkrlik, L., KernHansen, C., Heino, R., Bessemoulin, P., Müller-Westermeier, G., Tzanakou, M., Szalai, S., Pálsdóttir, T., Fitzgerald, D., Rubin, S., Capaldo, M., Maugeri, M., Leitass, A., Bukantis, A., Aberfeld, R., Engelen, van Engelen, A. F. V., Førland, E., Mietus, M., Coelho, F., Mares, C., Razuvaev, V., Nieplova, E., Cegnar, T., López, J. A., Dahlström, B., Moberg, A., Kirchhofer, W., Ceylan, A., Pachaliuk, O., Alexander, L. V., and Petrovic, P.: Daily dataset of 20th-century surface air temperature and precipitation series for the European Climate Assessment, Int. J. Climatol., 22, 1441-1453, 2002.

Orskaug, E., Scheel, I., Frigessi, A., Guttorp, P., Haugen, J., Tveito, O., and Haug, O.: Evaluation of a dynamic downscaling of precipitation over the Norwegian mainland, Tellus, 63, 746-756, 2011.

Pall, P., Allen, M. R., and Stone, D. A.: Testing the Clausius-Clapeyron constraint on changes in extreme precipitation under $\mathrm{CO}_{2}$ warming, Clim. Dynam., 28, 351-363, https://doi.org/10.1007/s00382-006-0180-2, 2007.

Papalexiou, S. M. and Koutsoyiannis, D.: Battle of extreme value distributions: A global survey on extreme daily rainfall, Water Resour. Res., 49, 187-201, https://doi.org/10.1029/2012WR012557, 2013.

Press, W. H., Flannery, B. P., Teukolsky, S. A., and Vetterling, W. T.: Numerical Recipes in Pascal, Cambridge University Press, Cambridge, UK, 1989.

Sanderson, B. M., Knutti, R., and Caldwell, P.: Addressing Interdependency in a Multimodel Ensemble by Interpolation of Model Properties, J. Climate, 28, 5150-5170, https://doi.org/10.1175/JCLI-D-14-00361.1, 2015.

Stocker, T. F., Qin, D., Plattner, G.-K., Tignor, M., Allen, S. K., Boschung, J., Nauels, A., Xia, Y., Bex, V., and Midgley, M.: Climate Change 2013: The Physical Science Basis. Contribution of Working Group I to the Fifth Assessment Report of the Intergovern - mental Panel on Climate Change, Cambridge University Pres, Cambridge, United Kingdom and New York, NY, USA, 2013.

Strang, G.: Linear Algebra and its Application, Harcourt Brace \& Company, San Diego, California, USA, 1988.

Takayabu, I., Kanamaru, H., Dairaku, K., Benestad, R., Storch, H. V., and Christensen, J. H.: Reconsidering the quality and 
utility of downscaling, J. Meteorol. Soc. Jpn., 94, 31-45, https://doi.org/10.2151/jmsj.2015-042, 2015.

Taylor, K. E., Stouffer, R. J., and Meehl, G. A.: An Overview of CMIP5 and the Experiment Design, B. Am. Meteorol. Soc., 93, 485-498, https://doi.org/10.1175/BAMS-D-11-00094.1, 2012.
Trenberth, K. E., Dai, A., Rasmussen, R. M., and Parsons, D. B.: The changing character of precipitation, B. Am. Meteorol. Soc. 84, 1205-1218, 2003. 